enough to detect small amounts of possibly abnormal serum ferritin derived from leukaemic cells. Isoelectric focusing techniques have shown characteristic isoferritin profiles for several normal tissues and immunological differences can also be shown using specific antisera. ${ }^{4}$ If immunological differences between leukaemic and normal ferritins exist it may be possible to produce an antibody directed against leukaemic cell ferritin; assays using such an antibody might be expected to yield data of clinical relevance in acute leukaemia.

We thank the many haematologists who sent specimens and information about patients. This work was supported by a grant from the Medical Research Council and was carried out in collaboration with the Medical Research Council's Working Party on Leukaemia in Childhood.

${ }^{1}$ Parry, D H, Worwood, M, and Jacobs, A, British Medical fournal, 1975, 1, 245.

2 Jones, B M, and Worwood, M, Fournal of Clinical Pathology, 1975, 28, 540.

3 Peto, R, et al, British Fournal of Cancer, 1977, 35, 1.

1 Wagstaff, M, Worwood, M, and Jacobs, A, Biochemical fournal, 1978, 173, 969 .

(Accepted 8 September 1978)

Department of Haematology, Welsh National School of Medicine, Heath Park, Cardiff

D H PARRY, MB, MRCPATH, lecturer

C RICKETTS, PHD, scientific officer

A JACOBS, MD, FRCPATH, professor

\section{Antibiotics and respiratory illness in general practice: prescribing policy and work load}

Twenty-five million prescriptions for antibiotics are written by general practitioners annually for new episodes of respiratory illness. ${ }^{1}$ Apart from the treatment of relevant morbidity the belief remains that withholding antibiotics creates extra subsequent work, particularly work "out-of-hours." This retrospective study examines the relationship between antibiotic prescribing policy on new respiratory illness and consulting patterns in a group practice.

\section{Patients, methods, and results}

The practice was a three-partner one caring for some 6000 city patients. A fourth doctor worked in the practice on a regular part-time basis and a trainee was employed. The following three groups of patients, all registered continuously with the practice since birth, were studied: (1) all 50 born in $1970,(2)$ all 60 born in 1960 , (3) all 43 born in 1950 and 1951. The study covered the seven years 1970-6. For each consultation for a new respiratory symptom a note was made of the doctor consulting, any antibiotic prescribed, and any further consultation within two weeks and what was then prescribed. "Failure" of treatment was defined as the prescription of either an antibiotic within two weeks of a new consultation at which no antibiotic had been prescribed or a change of antibiotic for a patient who had received an antibiotic at a new respiratory consultation within the previous two weeks.

Out of 856 new respiratory consultations antibiotics were prescribed at
$639(75$ " $): 53$ "failures" of treatment were noted, an incidence of 6 ". The "failure" rate was the same for all doctors working in the practice although the antibiotic prescribing policies ranged widely from $48 \%$ to $88^{\circ} \%$ (table). Antibiotics were prescribed at $73^{\circ}$ " of 521 consultations with the youngest group of patients and $8^{\circ}$ of consultations were failures. The trainees had double the failure rate $\left(11^{\prime \prime}{ }_{1}\right)$ of the more experienced doctors $\left(6{ }^{\prime}\right)$ in this age group. There were only five failures in the 216 consultations with the intermediate age group ( $77^{\circ}$, received antibiotics). Out of 119 consultations with young adults $79^{\prime \prime}$, received antibiotics and $7 \%$, failed. Twenty of the 53 failures occurred after not prescribing an antibiotic at the first consultation and 33 arose despite prescribing an antibiotic at the first consultation. An expected new respiratory illness consultation rate for the patients studied was estimated from the National Morbidity Study." The ratio of actual to expected consultations in the 0-6 age group was 521:392 (an excess of 33 ".), in the 10-16 age group 216:156 (an excess of 38\%), and in the 20-26 age group 120:102 (an excess of $18^{\circ}$ ). The overall expected figure of 650 consultations was exceeded by $31 \%$ at a total of 856 consultations.

\section{Comment}

Only limited conclusions may be drawn from a retrospective study of even good practice records. The apparent discrepancy in the amount of work attributed to the three partners is explained thus: partner one sees more elderly patients; partner two consults faster than his colleagues and sees more patients overall; partner three joined the practice three years after the start of the study period (there is no evidence that his prescribing to very young infants was different from his overall prescribing policy for young children). A policy of high antibiotic prescribing apparently does not reduce the number of patients seeking further consultation and change of treatment in the acute phase of the illness. An overall policy of prescribing antibiotics to three patients out of four with new respiratory illness (three out of five is the area average ${ }^{3}$ ) apparently creates more follow-up work attributable to changing antibiotics than to having to initiate them. Trainees seem less able to prescribe effectively to children (or to "sell" their initial management policy to the parents) than are more experienced doctors. An above average practice antibiotic prescribing frequency appears to be associated with an above average respiratory illness consultation rate.

The absence of any support for the belief that prescribing antibiotics on a large scale saves work may, in conjunction with other recent work, ${ }^{45}$ encourage doctors to make the initial move towards educating and away from prescribing that should eventually snowball to the benefit of doctor, patient, and society.

We thank Drs J Gauld, I Ross, and R Strachan for their interest and for access to their practice records.

1 British Medical fournal, 1974, 3, 1.

2 Office of Population Censuses and Surveys, Morbidity Statistics from General Practice, Studies on Medical and Population Subjects No 26. London, HMSO, 1974.

${ }^{3}$ Howie, J G R, et al, fournal of the Royal College of General Practitioners, 1971, 21, 657.

Marsh, G N, British Medical fournal, 1977, 2, 1267.

Thomas, K B, British Medical fournal, 1978, 1, 1327.

(Accepted 4 September 1978)

Department of General Practice, University of Aberdeen, Aberdeen J G R HOWIE, MD, MRCGP, senior lecturer

Aberdeen

K R HUTCHISON, MB, trainee general practitioner 